\title{
Oligonucleotide Purification
}

National Cancer Institute

\section{Source}

National Cancer Institute. Oligonucleotide Purification. NCI Thesaurus. Code C113063.

The processing of separating full-length olig onucleotides from incomplete chains and reagents. 